\title{
Replication and exploratory analysis of 24 candidate risk polymorphisms for neural tube defects
}

Faith Pangilinan ${ }^{1}$, Anne M Molloy ${ }^{2}$, James L Mills ${ }^{3}$, James F Troendle ${ }^{4}$, Anne Parle-McDermott ${ }^{5}$, Denise M Kay ${ }^{6}$, Marilyn L Browne ${ }^{7,8}$, Emily C McGrath ${ }^{6}$, Hatice Ozel Abaan ${ }^{1}$, Marie Sutton ${ }^{9}$, Peadar N Kirke ${ }^{10}$, Michele Caggana ${ }^{6}$, Barry Shane ${ }^{11}$, John M Scott ${ }^{12^{\wedge}}$ and Lawrence C Brody ${ }^{1 *}$

\begin{abstract}
Background: Neural tube defects (NTDs), which are among the most common congenital malformations, are influenced by environmental and genetic factors. Low maternal folate is the strongest known contributing factor, making variants in genes in the folate metabolic pathway attractive candidates for NTD risk. Multiple studies have identified nominally significant allelic associations with NTDs. We tested whether associations detected in a large Irish cohort could be replicated in an independent population.

Methods: Replication tests of 24 nominally significant NTD associations were performed in racially/ethnically matched populations. Family-based tests of fifteen nominally significant single nucleotide polymorphisms (SNPs) were repeated in a cohort of NTD trios (530 cases and their parents) from the United Kingdom, and case-control tests of nine nominally significant SNPs were repeated in a cohort (190 cases, 941 controls) from New York State (NYS). Secondary hypotheses involved evaluating the latter set of nine SNPs for NTD association using alternate case-control models and NTD groupings in white, African American and Hispanic cohorts from NYS.

Results: Of the 24 SNPs tested for replication, ADA rs452159 and MTR rs 10925260 were significantly associated with isolated NTDs. Of the secondary tests performed, ARIDIA rs 11247593 was associated with NTDs in whites, and ALDH1A2 rs7169289 was associated with isolated NTDs in African Americans.

Conclusions: We report a number of associations between SNP genotypes and neural tube defects. These associations were nominally significant before correction for multiple hypothesis testing. These corrections are highly conservative for association studies of untested hypotheses, and may be too conservative for replication studies. We therefore believe the true effect of these four nominally significant SNPs on NTD risk will be more definitively determined by further study in other populations, and eventual meta-analysis.
\end{abstract}

Keywords: Neural tube defects, Spina bifida, Folate, Folic acid, One-carbon metabolism, Replication

\footnotetext{
* Correspondence: Ibrody@mail.nih.gov

Deceased

${ }^{1}$ Molecular Pathogenesis Section, Genome Technology Branch, National

Human Genome Research Institute, National Institutes of Health, Room 5306,

50 South Drive, Bethesda, MD 20892-8004, USA

Full list of author information is available at the end of the article
}

\section{Biomed Central}

(c) 2014 Pangilinan et al.; licensee BioMed Central Ltd. This is an Open Access article distributed under the terms of the Creative Commons Attribution License (http://creativecommons.org/licenses/by/4.0), which permits unrestricted use, distribution, and reproduction in any medium, provided the original work is properly credited. The Creative Commons Public Domain Dedication waiver (http://creativecommons.org/publicdomain/zero/1.0/) applies to the data made available in this article, unless otherwise stated. 


\section{Background}

Neural tube defects (NTDs) are common, severe birth defects that affect the development of the spinal cord and/or brain. NTDs mainly present as spina bifida, anencephaly and encephalocele. Although the NTD rate has been reduced in areas with folic acid fortification [1-4], reported NTD rates include 1 in 1000 births in the US [5,6], 0.1-1.1 in 1000 births in Europe [7], 1-4.8 in 1000 pregnancies in China [3], 3.9-8.8 in 1000 births in India [8], and 0.2-9.6 in 1000 births in Latin America [9]. Both environmental and genetic factors are involved in the development of NTDs. In western countries, dietary folate is the strongest known environmental factor. Mothers with an NTD pregnancy have significantly lower levels of folate [10], and periconceptional folate supplementation can lower NTD risk by $50-70 \%[3,11,12]$. The most firmly established genetic factor is a common polymorphism (rs1801133, c.677C $>\mathrm{T}$ ) in the 5, 10methylene-tetrahydrofolate reductase (MTHFR) gene. The alternate nucleotide in this single nucleotide polymorphism (SNP) changes an alanine to a valine (p.A222V), resulting in a thermolabile form of the protein [13]. The MTHFR c.677 TT genotype has been significantly associated with NTD cases in many populations (reviewed in $[14,15]$ ). Other NTD risk SNPs have been identified in a number of populations (e.g., rs2236225 (c.1958G > A, p.R653Q) in methylenetetrahydrofolate dehydrogenase (NADP + dependent) 1 , methenyltetrahydrofolate cyclohydrolase, formyltetrahydrofolate synthetase (MTHFD1) [16-21], rs1805087 (c.2756A > G, p.D919G) in methionine synthase (MTR) [15,16,22-29], rs1051266 (c.80A > G, p. $\mathrm{H} 27 \mathrm{R}$ ) in the reduced folate carrier (RFC1/SLC19A1) [15,21,30-33]), and rs70991108 (19 bp indel; c.86+ 59_86 + 60insACCTGGGCGGGACGCGCCA) in dihydrofolate reductase (DHFR) [34-36]). The majority of associations have not been subjected to robust replication.

Rigorously establishing genetic risk for any multifactorial disorder is important but inherently difficult. Genetic risk is optimally detected with a large number of racially/ethnically homogenous samples that include cases with a well-defined, highly penetrant phenotype. These are difficult criteria to meet for rare, complex disorders, meaning that statistical power is often compromised to some extent. This, in combination with the bias that significant associations are more likely to be published [37-40], contributes to many associations in the literature that would not survive correction for multiple tests.

Specifically in the field of genetic risk for NTDs, studies including large numbers of candidate polymorphisms and/ or genes have implicated many candidate SNPs exhibiting nominal NTD associations [21,41-45]. Each of the cited studies examined a minimum of 37 SNPs for NTD risk, yet only the association of rs1907362 in cubilin (CUBN) with NTDs survived correction in the original study [21]. The most likely explanation is that the reported nominally significant associations were due to chance. However, the large number of tests performed, reduced power due to limited availability of samples, and/or the populationspecific effect of a risk allele can all contribute to Type II errors. Therefore replication studies are essential for the validation of any genetic risk factor for NTDs.

In one of the largest studies to date we previously reported evaluation of the common genetic variation in 82 candidate genes for NTD risk in an Irish population [45]. The inclusion of 570 NTD cases ( 95\% spina bifida cases), their parents and 999 controls made it possible to use both family based methods (the transmission disequilibrium test and log-linear analysis) and case-control based methods (logistic regression) to evaluate genetic risk for NTDs in cases (case effect) as well as genetic risk for an NTD pregnancy in mothers (maternal effect). In the current study, we test 24 of the resulting nominally significant association signals using 9 casecontrol tests and 14 family-based tests in racially/ethnically similar populations. The 9 SNPs that showed nominal significance by case-control analysis in the previously studied Irish NTD cohort were additionally evaluated for NTD risk using varying models in racially/ethnically similar and distinct populations.

\section{Methods}

\section{Statistical methods}

For replication analyses, each candidate risk allele was retested using the same association test and model for which it was nominally significant in the primary study. These tests are noted in Tables 1 and 2, and include: 1 ) case-control tests of logistic regression using a continuous, recessive or dominant genetic model; 2) log-linear tests of case or maternal effect using a dominant or recessive genetic model; and 3) the Spielman transmission disequilibrium test (TDT [46]).

Secondary hypotheses involved more broadly testing the candidate SNPs for NTD risk in other populations and/or NTD classifications. Three models (continuous, recessive and dominant) of logistic regression were performed to generate genotype relative risks (GRRs) and $95 \%$ confidence intervals $(\mathrm{CI})$.

\section{Study populations}

Family-based replication was performed in a United Kingdom cohort consisting of trios of NTD cases and their parents. Exclusion of the "Other NTDs" class, which may include a small number of families with multiple defects or spina bifida occulta, did not substantially change the results. This cohort consists of three groups (Table 3). First, the 400 case families recruited with the assistance of the UK Association for Spina Bifida and 
Table 1 Case-control replication analyses in the New York State NTD cohort

\begin{tabular}{llll}
\hline Gene SNP & Test/Model* & $\begin{array}{l}\text { Result in Irish NTD Cohort [45] } \\
\text { GRR [95\% Cl], p-value }\end{array}$ & $\begin{array}{l}\text { Result in NYS NTD Cohort } \\
\text { GRR [95\% Cl], p-value }\end{array}$ \\
\hline ADA rs6031682 & LR CC Dom & $0.67[0.52-0.86], p=0.0016$ & $0.92[0.63-1.33], p=0.653$ \\
ALDH1A2 rs7169289 & LR CC Dom & $0.71[0.56-0.90], p=0.0043$ & $1.07[0.77-1.47], p=0.697$ \\
ARID1A rs11247593 & LR CC Cont & $1.35[1.11-1.64], p=0.0027$ & $0.81[0.63-1.04], p=0.092$ \\
CDKN2A rs7041637 & LR CC Cont & $0.69[0.53-0.89], p=0.0048$ & $1.07[0.85-1.36], p=0.564$ \\
CTH rs12733999 & LR CC Rec & $0.57[0.39-0.84], p=0.0048$ & $1.12[0.65-1.92], p=0.692$ \\
ENOSF1 rs1059384 & LR CC Rec & $1.84[1.23-2.75], p=0.0028$ & $0.98[0.60-1.60], p=0.937$ \\
FOLH1 rs383028 & LR CC Cont & $0.58[0.39-0.85], p=0.0051$ & $1.07[0.76-1.52], p=0.697$ \\
MFTC rs17803441 & LR CC Cont & $0.62[0.48-0.81], p=0.0003$ & $1.02[0.66-1.58], p=0.922$ \\
MTHFD1L rs2295083 & LR CC Rec & $0.60[0.43-0.85], p=0.0038$ & $1.25[0.89-1.76], p=0.193$ \\
\hline
\end{tabular}

*LR CC = logistic regression, case-control; genetic models: Dom (dominant), Cont (continuous) and Rec (recessive).

Hydrocephalus (ASBAH) (England and Wales) are fully described elsewhere [47]. Second, 131 case families were recruited from Northern Ireland. Ethical approval of the use of these samples was granted by the UK MultiCentre Research Ethics Committee (University of Newcastle, UK, and University of Northern Ireland, Coleraine) and the Institutional Review Board at the National Human Genome Research Institute (Bethesda, MD, USA).

Replication of findings from case-control analyses was performed in a NYS case-control cohort. NTD cases from the entire state born 1998-2005 were identified by their inclusion in the NYS Congenital Malformations Registry (NYSCMR). Matched controls were selected as a random sample of non-malformed control infants born 1998-2005 from NYS Newborn Screening Program records. Demographic data was obtained by matching to NYS birth certificates. Four controls matched for maternal race/ethnicity were selected for each NTD case. Due to low numbers, the Asian and "other" racial/ethnic subgroups were excluded, and subjects coded as "Hispanic, white" and "Hispanic, other" were combined into a single Hispanic group for analysis. Case diagnoses allowed classification of the NTDs into six subgroups based on NTD subtype (anencephaly, encephalocele, spina bifida) and whether the NTD was isolated or part of multiple defects (Table 4). To perform the replication analyses, only isolated NTDs of all three subtypes among the NHWs were considered in order to most closely match the composition of the NTD cases in the original Irish cohort. Secondary hypotheses involved analyses of: 1) all

Table 2 Family-based replication analyses in the combined United Kingdom NTD cohort

\begin{tabular}{llll}
\hline Gene SNP & Test/Model* & Result in Irish NTD Cohort [45] & $\begin{array}{c}\text { Result in UK Cohort } \\
\text { GRR [95\% Cl], p-value }\end{array}$ \\
\hline ADA rs452159 & GRR [95\% Cl], p-value & $1.86[1.01-3.40], p=0.045$ \\
CDKN2A rs3218009 & LL Case Dom & $2.28[1.29-4.05], p=0.0047$ & $1.16[0.81-1.65], p=0.418$ \\
COMT rs174675 & LL Mat Dom & $2.32[1.45-3.71], p=0.0004$ & $0.89[0.55-1.43], p=0.621$ \\
CUBN rs11254375 & LL Case Dom & $0.41[0.23-0.73], p=0.0028$ & $1.22[0.89-1.66], p=0.210$ \\
DNMT3A rs7560488 & LL Mat Dom & $1.48[1.10-1.99], p=0.0097$ & $0.89[0.61-1.28], p=0.520$ \\
DNMT3B rs6058896 & LL Case Rec & $2.10[1.31-3.38], p=0.0021$ & $1.18[0.77-1.82], p=0.443$ \\
FOLH1 rs16906205** & TDT & $1.88[1.24-2.85], p=0.0029$ & $1.10[0.75-1.63], p=0.619$ \\
GART rs2070388 & LL Mat Dom & $0.43[0.23-0.78], p=0.0060$ & $0.73[0.52-1.03], p=0.070$ \\
GNMT rs9462856 & TDT & $0.53[0.36-0.78], p=0.0012$ & $1.19[0.85-1.68], p=0.308$ \\
MAT2B rs17535909 & LL Case Dom & $0.55[0.36-0.83], p=0.0048$ & Failed genotyping \\
MTHFD1 rs11627525 & LL Case Rec & $1.69[1.18-2.42], p=0.0045$ & $1.13[0.76-1.68], p=0.545$ \\
MTHFD1 rs2236225 & LL Mat Rec & $2.17[1.24-3.79], p=0.0067$ & $1.21[0.84-1.74], p=0.299$ \\
MTR rs10925260 & LL Case Dom & $1.66[1.16-2.37], p=0.0054$ & $0.71[0.53-0.94], p=0.019$ \\
PEMT rs4646402 & LL Case Rec & $0.64[0.48-0.86], p=0.0031$ & $0.92[0.70-1.23], p=0.585$ \\
PEMT rs16961845 & LL Case Dom & $0.600[0.46-0.8], p=0.0005$ & $0.73[0.46-1.15], p=0.171$ \\
\hline
\end{tabular}

*LL; = log-linear analysis; TDT = transmission disequilibium test; Case = case effect; Mat = maternal effect; genetic models: Dom (dominant) and Rec (recessive). **Proxy SNP (FOLH1 rs11040291; $\mathrm{r}^{2}=1$ in Hapmap CEU) results shown for replication. 
Table 3 Number of NTD family members in the UK family-based cohort

\begin{tabular}{lllll}
\hline & England & $\begin{array}{l}\text { Northern } \\
\text { Ireland }\end{array}$ & Wales & Total \\
\hline Spina bifida & 331 & 122 & 26 & 479 \\
Encephalocele & 7 & 5 & 1 & 13 \\
Spina bifida and Encephalocele & 2 & 0 & 0 & 2 \\
Other NTDs* & 28 & 4 & 5 & 37 \\
Total NTD Cases & 368 & 131 & 32 & 531 \\
NTD Mothers & 321 & 121 & 30 & 472 \\
NTD Fathers & 263 & 105 & 21 & 389 \\
\hline
\end{tabular}

*May include NTD in the context of multiple defects or spina bifida occulta.

NTD cases and all controls, stratified by race/ethnicity; and 2) isolated spina bifida cases and corresponding matched controls. Approval for the use of the deidentified samples was granted by the New York State Department of Health Institutional Review Board and the NIH Office for Human Research Protections.

\section{Genotyping}

MTHFD1 rs2236225 was genotyped in the UK cohort as a restriction fragment length polymorphism (PCR-RFLP) using $M s p \mathrm{I}$ as previously described [17,48]. Genotypes were obtained for $91.6 \%$ of NTD fathers, $92.5 \%$ of NTD cases and $93.6 \%$ of NTD mothers. Concordance was $100 \%$ for repeated $(n=83)$ and for re-plated (the testing of a second sample from the DNA source) $(\mathrm{n}=92)$ samples using an independent assay based on detection of allele-specific primer extension using matrix-assisted laser desorption/ionization - time of flight (MALDITOF) mass spectrometry (Sequenom, San Diego, CA, USA). The remaining SNPs in Table 2 were also genotyped in the UK cohort using the Sequenom platform. Two independent assays of folate hydrolase (FOLH1) rs16906205 failed, so the proxy FOLH1 rs11040291 $\left(\mathrm{r}^{2}=1\right.$ in Hapmap CEU) was genotyped and reported instead. Two independent assays to genotype methionine adenosyltransferase II, beta $(M A T 2 B)$ rs17535909, were attempted but both failed, and there was no proxy for this singleton
SNP. For this set of 13 SNPs, the average call rates were $\geq 96.8 \%$ for each family group (NTD cases, NTD mothers or NTD fathers). Re-plated and re-genotyped samples covered $>18 \%$ of the cohort with $99.2 \%$ genotype concordance for this set of 13 SNPs. The 14 SNPs typed in the UK cohort exhibited non-Mendelian inheritance in $<1 \%$ of families. These SNPs were also in Hardy Weinberg Equilibrium (HWE, p > 0.01) for each family group. Genotypes for families exhibiting nonMendelian inheritance and other discordant genotypes were excluded from analysis.

For NYS samples, DNA was extracted from one 3-mm archived dried blood spot specimen [49] and whole-genome amplified using a primer extension preamplification method, as described previously [50]. SNPs were genotyped by KBiosciences (Herts, UK) using KASPar chemistry. Eight SNPs were genotyped in duplicate using independently whole-genome amplified DNA aliquots with $100 \%$ concordance in genotype calls. FOLH1 rs383028 was genotyped using genomic DNA because data from amplified DNA did not pass quality control criteria. The average call rate for 9 SNPs (Table 1) was 99.9\% for both cases and controls. Replated samples covered $6.5 \%$ of the cohort with genotype concordance of $100 \%$. No SNPs deviated from HWE $(p>0.01)$ in any case or control group for any race/ethnicity.

\section{Results}

The primary aim of this study was to perform replication analyses of the nominally significant NTD associations identified in a recent study in an Irish population [45]. The secondary aim was to test a subset of these candidate SNPs for association using alternate risk models and populations.

\section{Replication analyses \\ Replication criteria}

The replication strategy was designed to retest nominally significant NTD-associated SNPs in racially/ethnically matched populations using the same association tests and genetic models that previously yielded the

Table 4 Number of NTD cases and controls by race/ethnicity in the NY state cohort

\begin{tabular}{|c|c|c|c|c|c|c|c|}
\hline & White, non-Hispanic & AA, non-Hispanic & Hispanic, white & Hispanic, other & Asian* & Other/Unknown* & Total \\
\hline Isolated anencephaly & 7 & 2 & 1 & 1 & 0 & 0 & 11 \\
\hline Isolated encephalocele & 22 & 10 & 12 & 5 & 1 & 1 & 51 \\
\hline Isolated spina bifida & 161 & 65 & 65 & 13 & 16 & 2 & 322 \\
\hline Anencephaly - multiple defects & 2 & 3 & 1 & 0 & 1 & 0 & 7 \\
\hline Encephalocele - multiple defects & 16 & 5 & 4 & 1 & 0 & 0 & 26 \\
\hline Spina bifida - multiple defects & 25 & 13 & 11 & 1 & 2 & 0 & 52 \\
\hline Total NTD cases & 233 & 98 & 94 & 21 & 20 & 3 & 469 \\
\hline Controls & 941 & 408 & 393 & 87 & 91 & 12 & 1932 \\
\hline
\end{tabular}

*Excluded from analysis due to low numbers. 
lowest p-values among 1441 SNPs in 82 candidate genes tested in an Irish population [45]. Case-control association tests were performed in a cohort of 190 isolated NTD cases and 941 controls from non-Hispanic white (NHW) mothers from NYS, and family-based tests were performed in NTD trios $(n=530)$ consisting of NTD cases and their parents from the United Kingdom, including centers in Northern Ireland, England and Wales.

The top 25 groups of SNPs sharing high linkage disequilibrium (LD; D'>0.9) with the lowest p-values for any test were selected for replication (52 SNPs total). Without access to NTD mothers and corresponding controls several loci could not be retested. This included 9 independent mother-control signals (17 SNPs) in adenosine deaminase $(A D A)$, alcohol dehydrogenase 1 family, member A2 (ALDH1A2), catechol-O-methyltransferase (COMT), CUBN, MTHFD1, methylenetetrahydrofolate dehydrogenase (NADP + dependent) 1-like (MTHFD1L), brachyury (T), and transcription factor AP-2 alpha (TFAP2A). Of the remaining 35 SNPs, the SNP with the lowest observed p-value was selected for replication testing whenever SNPs with a minimum $\mathrm{p}$-value for the same test and model shared high LD $\left(\mathrm{D}^{\prime}>0.9\right)$. This reduced the number of tests to 24 (9 case-control tests and 15 family-based tests). Results of these tests are shown in Tables 1 and 2 .

\section{Replication of associations detected in case-control analyses}

We used the NTD case samples from NYS to replicate case effects previously observed in the Irish NTD cohort. Each SNP was tested for association with NTDs by logistic regression with the same genetic model used for the original observation. No SNP was observed to be significantly associated with isolated NTDs in white cases from NYS (Table 1). This lack of replication was accompanied by the corresponding genotype relative risk (GRR) values indicating an inconsistent effect of the candidate risk allele to that observed in the original study for eight of the nine SNPs.

\section{Replication of associations detected in family-based analyses}

Replication analyses of previously observed case or maternal effects detected by log-linear analysis were repeated with the same genetic model in a combined cohort of NTD triads from the United Kingdom. Two SNPs showed nominally significant association with NTDs: $A D A$ rs452159 in a dominant model $(\mathrm{GRR}=1.86$ [1.01-3.40], $\mathrm{p}=0.045)$, and $M T R$ rs10925260 in a recessive model $(\mathrm{GRR}=0.71[0.53-$ 0.94], $\mathrm{p}=0.019$ ). In both cases, the magnitude of the effect and the specific risk allele was similar to the original observation in the Irish NTD cohort (Table 2). If applied, the significance of these results would not withstand Bonferroni correction for multiple tests when considering all SNPs tested in the current study. In contrast to the case-control analyses, the direction of effect for the GRRs of these family-based associations largely agreed between the initial and replication studies (10 of 14), regardless of significance.

\section{Secondary hypotheses - exploratory analyses in new populations \\ Applying analyses that yielded nominal associations from the initial study}

In addition to replication, these candidate SNPs were tested for association in other NTD populations using various models. The nine SNPs selected for case-control replication in the NYS cohort were first tested in African American and Hispanic cases with an isolated NTD and controls using the same tests and models for which each SNP had been originally observed to be nominally associated in the Irish population (Table 1, 2 tests/SNP). Of the nine SNPs examined in each of the two racial/ethnic groups, only one, $A L D H 1 A 2$ rs7169289, was found to be nominally associated with isolated NTDs - in African Americans in a continuous model (GRR $=0.57$ [0.34-0.98], $\mathrm{p}=0.041$ ). This "protective" effect is in contrast to the risk effect seen for this SNP in the Irish cohort using a dominant model.

\section{Case-control analyses in all NTD cases vs. isolated Spina Bifida cases}

These SNPs were also tested by performing logistic regression using three genetic models (continuous, dominant and recessive) in all NTD cases and controls in each of the three racial/ethnic groups ( 9 tests/SNP). Of these nine SNPs tested in nine models $(\mathrm{N}=81$ tests), AT rich interactive domain 1A (ARID1A) rs11247593 was the only SNP found to be nominally associated with NTDs - in non-Hispanic whites in a dominant model $(G R R=0.58$ [0.35-0.97], $\mathrm{p}=0.037$ ). This protective effect is in contrast to the risk effect $(G R R>1)$ seen in the Irish cohort using a continuous model (Table 1).

Lastly, the same tests were performed in a restricted subset of isolated spina bifida cases and controls in the three racial/ethnic groups ( 9 tests/SNP). These 81 tests generated two significant findings: ALDH1A2 rs7169289 was nominally associated with isolated spina bifida cases in the African American population in continuous $(\mathrm{GRR}=0.46$ [0.25-0.87], $\mathrm{p}=0.017)$ and dominant $(\mathrm{GRR}=$ 0.47 [0.24-0.94], $\mathrm{p}=0.033$ ) models. Similarly, a significant risk effect was observed in the original Irish population, but not the NYS NHW population (Table 1).

These results are summarized in Table 5. These results are nominally significant, though would not withstand Bonferroni correction using the total number of tests as the correction factor. 
Table 5 Nominally significant associations in the New York state cohort - secondary hypotheses

\begin{tabular}{llllll}
\hline Gene SNP & Race/ Ethnicity & Freq Risk Allele & NTD & Test/Model & GRR [95\% Cl], p-value \\
\hline ALDH1A2 rs7169289 & AA & 0.17 & Isolated NTDs & LR Cont & $0.57[0.34-0.98], p=0.041$ \\
ARID1A rs11247593 & NHW & 0.75 & All NTDs & LR Dom & $0.58[0.35-0.97], p=0.037$ \\
ALDH1A2 rs7169289 & AA & 0.17 & Isolated SB & LR Cont & $0.46[0.25-0.87], p=0.017$ \\
ALDH1A2 rs7169289 & AA & 0.17 & Isolated SB & LR Dom & $0.47[0.24-0.94], p=0.033$ \\
\hline
\end{tabular}

\section{Discussion}

Our study addressed two questions. First, are SNPs that were nominally significant upon testing for NTD association in an Irish population also associated with NTDs in a similar, independent population? Second, are the SNPs that were nominally significant upon testing for NTD association in an Irish population by logistic regression also associated with NTDs in different racial/ ethnic populations when using a broader range of association tests, genetic models and NTD case groupings?

Our criteria for replication were stringent, and only performed for a SNP when the same association test and genetic model could be applied. Because we did not have samples from mothers of NYS NTD cases, we were unable to test for a maternal risk for nine independent mother-control signals in seven genes. Nine SNPs were re-tested for a case effect by logistic regression in a white NTD sample from NYS, and log-linear analyses were used to re-test ten SNPs for a case effect and five SNPs for a maternal effect in a UK NTD sample. Of 14 SNPs previously observed to be associated with NTDs by family-based analysis in an Irish population, two showed nominally significant NTD association in trios from the UK (Table 2). ADA rs452159 falls in the first intron, and is at the border of a D' block encompassing the first exon and intron of the gene. MTR rs10925260 is in intron 23 of the gene, and is part of a large block of D' LD encompassing the entire gene. Due to their strong D' linkage, these nominally significant associations may reflect a direct signal or that of a causative SNP linked to the tested $\operatorname{SNP}(\mathrm{s})$.

Although none of the 9 SNPs found to be nominally significant in Irish NTDs were replicated in isolated NYS white NTD cases, two were nominally associated with NTDs under different conditions. ARID1A rs11247593 did not replicate by logistic regression using a continuous model in isolated NTDs (Table 1), but was significant when all white NTD cases and controls were tested using a dominant model (Table 5). ARID1A rs11247593 is intronic and is part of a large D' block extending over the entire gene, so the signal may be due to the tested SNP or a linked causative SNP. In addition, ALDH1A2 rs7169289 was significantly associated with isolated NTDs and isolated spina bifida cases in the African American population (Table 5). These results most likely represent a single association signal as the genetic models (continuous, dominant) and NTD sets (isolated NTDs, isolated SB) for these analyses overlap. The estimated effects observed in African American NTD cases from NYS (Table 5; OR $=0.46-0.57, \mathrm{p}=0.017-0.041$ ) are similar to the original effect observed in an Irish population (Table 1; OR =0.67 [0.52-0.86], $\mathrm{p}=0.0016$ ). ALDH1A2 rs7169289 is just downstream of the gene. It falls between two blocks of D' LD, and the association signal may be due to this SNP or a linked SNP in either block.

As was found in the original study, none of the observed associations in the NYS and UK sample sets would have survived correction for multiple tests. One interpretation is that these associations are indeed due to chance and that the tested SNPs do not contribute to NTD risk. It is not clear, however, that Bonferroni correction is appropriate for replication studies. All the tests performed in this study were clearly based on individual, a priori hypotheses generated for our initial study and supported by previous data. Additionally, factors that can contribute to Type II error should be considered, such as population stratification and genetic heterogeneity.

The most important factor may be limited sample size, which compromises the power to detect true associations. Compared to the number of NTD cases $(\mathrm{n} \sim 570)$ in the original Irish cohort, a limited number of white NYS isolated NTD cases $(n \sim 190)$ were available in the current study. With $~ 530$ NTD trios, however, the UK NTD cohort appears comparable, but this is before taking into consideration the power required to replicate an association. Due to the "winner's curse," or the tendency of an initial observation to overestimate the effect size or significance of a true association, replication studies generally require larger study sample numbers to detect the original effect $[51,52]$. This may explain why the well known NTD risk allele of MTHFR rs1801133 (T) is not associated with NTDs by TDT $(\mathrm{p}=0.742)$ in our large UK NTD cohort. In fact, it is nominally significant as a protective factor in a recessive model by log-linear analysis $(G R R=0.663$ [0.441-0.997], $\mathrm{p}=0.049)$. Considering that this association has been replicated in many studies in other populations supporting its role in NTD risk, it would be surprising if the MTHFR rs1801133 TT genotype does not contribute to NTDs in the UK population. A lack of replication power and chance seem the most likely explanations for this failure to replicate, which must be taken into consideration for the other SNPs 
tested for replication in this study. Authentic validation of any genetic association requires accumulation of evidence over time, involving multiple studies in independent populations.

Lack of adequate power is a pervasive problem in the field of NTD genetics. One recent review estimated that $\sim 1000$ cases would be required to attain $80 \%$ power to detect an odds ratio of 2 or under, yet approximately one quarter of published NTD association studies used fewer than 100 cases [53]. This problem is compounded when attempting to evaluate candidate risk SNPs in less studied populations. While we were able to examine candidate risk SNPs of interest in African American and Hispanic populations from NYS, far fewer cases were available compared to whites (Table 4). Although some population-based studies have included African American cases in aggregate analyses of genetic risk for NTDs [54-56], and there are studies of NTD risk in African cohorts [57], this is the first report of candidate NTD SNPs evaluated in an African American case-control cohort. The nominal association observed for ALDH1A2 rs7169289 may be real, but needs confirmation.

Identifying potential NTD risk SNPs has proven much easier than validating them. A single replication study is not definitive, and the limited numbers in existing NTD cohorts may contribute to subsequent underpowered studies failing to confirm reported associations. By combining data from multiple published studies, metaanalyses increase power and confidence in whether a SNP truly contributes to NTD risk. Meta-analyses involving aggregate data from several hundred to several thousand NTD cases and controls have confirmed MTHFR rs1801133 (c.677C > T) as a maternal [58] and case risk factor for NTDs [14,15,58,59]. Although comparatively fewer data were available, meta-analyses show 5-methyltetrahydrofolate-homocysteine methyltransferase reductase $(M T R R)$ rs1801394 $(\mathrm{c} / 66 \mathrm{~A}>\mathrm{G})$ is a maternal risk factor for NTDs [60,61], while MTR rs1805087 $(\mathrm{c} / 2756 \mathrm{~A}>\mathrm{G})$ does not contribute to maternal or case risk $[15,22,60,62]$. However, meta-analysis requires a large amount of data including full genotype information. These data are absent in publications for the majority of NTD risk SNPs that show nominal significance. It is therefore essential to publish all association study data in a format that allows future meta-analyses to be performed (i.e., genotype counts or a way to unambiguously determine them). As such, we have reported the genotype data for all 24. SNPs tested in our study (Additional file 1: Table S1 and Additional file 2: Table S2).

\section{Conclusions}

In summary, this study represents both the effort to validate nominally significant NTD associations via replication, and to test a subset of these SNPs in alternate NTD groupings and racial/ethnic populations. The NTD associations we observed with four SNPs would not have survived correction for multiple tests. However, we believe it would be overly severe to apply Bonferroni correction to $A D A$ rs452159 and MTR rs10925260, which were nominally significant by strict replication analysis, as well as ARID1A rs11247593, which was found to be associated by a different model and expanded definition of NTDs. Additionally, to our knowledge, this is the first report of a genetic association with NTDs in African Americans and so the nominal significance of $A L D H 1 A 2$ rs7169289 in the small NYS NTD cohort warrants follow-up. Further testing in independent populations and meta-analyses are needed to clarify the role of these and a multitude of nominally significant SNPs associated with NTDs.

\section{Additional files}

Additional file 1: Table S1. Genotype counts for candidate SNPs in the NTD cases, fathers and mothers from the United Kingdom (England, Wales, and Northern Ireland).

Additional file 2: Table S2. Genotype counts for candidate SNPS in the New York state NTD cases and controls by ethnicity and each analyzed NTD subtype.

\section{Abbreviations}

LD: Linkage disequilibrium; NTDs: Neural tube defects; SNP: Single nucleotide polymorphism; TDT: Transmission disequilibrium test; NYS: New York State; NHW: Non-Hispanic white; GRR: Genotype relative risk.

\section{Competing interests}

The authors declare that they have no competing interests.

\section{Authors' contributions}

FP, AMM, JLM, PNK, BS, JMS and LCB formulated the study design. FP drafted the manuscript. MS managed subject recruitment and data collection for the UK subjects. AMM managed the UK DNA samples and their selection. DK, MB, MC and ECM managed and selected the NYS DNA samples, and contracted their genotyping. FP, AP-M, and HA performed genotyping. JFT contributed to study design and performed the statistical analyses. All authors read, edited and approved the final manuscript.

\section{Acknowledgements}

These studies would not be possible without the participation of the affected families, and their recruitment by the United Kingdom Association of Spina Bifida and Hydrocephalus. The authors acknowledge research support from the Intramural Research programs of the National Human Genome Research Institute, the Eunice Kennedy Shriver National Institute of Child Health and Human Development (NICHD contract number: N01-DK-73431), and the Health Research Board, Ireland. We thank Dr. Charlotte Druschel, Director of the Congenital Malformations Registry, for identifying and reviewing cases for this investigation, and Sandra D. Richardson at the NYSCMR for subject selection and data management. We also thank April J. Atkins, Adam C. Gearhart, and Robert J. Sicko at the Wadsworth Center, New York State Department of Health for providing laboratory and technical assistance.

\section{Author details}

${ }^{1}$ Molecular Pathogenesis Section, Genome Technology Branch, National Human Genome Research Institute, National Institutes of Health, Room 5306, 50 South Drive, Bethesda, MD 20892-8004, USA. ²Department of Clinical Medicine, Trinity College Dublin, Dublin, Ireland. ${ }^{3}$ Division of Epidemiology, Statistics and Prevention Research, Eunice Kennedy Shriver National Institute 
of Child Health and Human Development, National Institutes of Health, Bethesda, MD, USA. ${ }^{4}$ Office of Biostatistics Research, National Heart Lung and Blood Institute, National Institutes of Health, Bethesda, MD, USA. ${ }^{5}$ School of Biotechnology, Dublin City University, Dublin, Ireland. ${ }^{6}$ New York State Department of Health, Division of Genetics, Wadsworth Center, Albany, NY 12201, USA. ${ }^{7}$ New York State Department of Health, Congenital Malformations Registry, Troy, NY 12180, USA. ${ }^{8}$ Department of Epidemiology and Biostatistics, School of Public Health, University at Albany, Rensselaer, NY 12144, USA. ${ }^{9}$ Evidence Centre, Health Research Board, Dublin, Ireland. ${ }^{10} \mathrm{Child}$ Health Epidemiology Unit, Health Research Board, Dublin, Ireland.

${ }^{11}$ Department of Nutritional Sciences and Toxicology, University of California, Berkeley, CA 94720-3104, USA. ${ }^{12}$ School of Biochemistry and Immunology, Trinity College Dublin, Dublin, Ireland.

Received: 12 March 2014 Accepted: 19 August 2014

Published online: 08 October 2014

\section{References}

1. Canfield MA, Honein MA, Yuskiv N, Xing J, Mai CT, Collins JS, Devine O, Petrini J, Ramadhani TA, Hobbs CA, Kirby RS: National estimates and race/ ethnic-specific variation of selected birth defects in the United States, 1999-2001. Birth Defects Res A Clin Mol Teratol 2006, 76:747-756.

2. Botto LD, Lisi A, Bower C, Canfield MA, Dattani N, De Vigan C, De Walle H, Erickson DJ, Halliday J, Irgens LM, Lowry RB, McDonnell R, Metneki J, Poetzsch S, Ritvanen A, Robert-Gnansia E, Siffel C, Stoll C, Mastroiacovo P: Trends of selected malformations in relation to folic acid recommendations and fortification: an international assessment. Birth Defects Res A Clin Mol Teratol 2006, 76:693-705.

3. Berry RJ, Li Z, Erickson JD, Li S, Moore CA, Wang H, Mulinare J, Zhao P, Wong $L Y$, Gindler J, Hong SX, Correa A: Prevention of neural-tube defects with folic acid in China. China-U.S. Collaborative Project for Neural Tube Defect Prevention. N Engl J Med 1999, 341:1485-1490.

4. Blencowe H, Cousens S, Modell B, Lawn J: Folic acid to reduce neonatal mortality from neural tube disorders. Int J Epidemiol 2010, 39(Suppl 1):i1 10-i121.

5. Congenital malformations worldwide: A Report from the International Clearinghouse for Birth Defects Monitoring Systems. Amsterdam: Elsevier Science Publishers; 1991.

6. Busby A, Abramsky L, Dolk H, Armstrong B: Preventing neural tube defects in Europe: population based study. BMJ 2005, 330:574-575.

7. Botto LD, Lisi A, Robert-Gnansia E, Erickson JD, Vollset SE, Mastroiacovo P, Botting B, Cocchi G, de Vigan C, de Walle H, Feijoo M, Irgens LM, McDonnell B, Merlob P, Ritvanen A, Scarano G, Siffel C, Metneki J, Stoll C, Smithells R, Goujard J: International retrospective cohort study of neural tube defects in relation to folic acid recommendations: are the recommendations working? BMJ 2005, 330:571.

8. Cherian A, Seena S, Bullock RK, Antony AC: Incidence of neural tube defects in the least-developed area of India: a population-based study. Lancet 2005, 366:930-931.

9. Rosenthal J, Casas J, Taren D, Alverson CJ, Flores A, Frias J: Neural tube defects in Latin America and the impact of fortification: a literature review. Public Health Nutr 2014, 17(3):537-550.

10. Kirke PN, Molloy AM, Daly LE, Burke H, Weir DG, Scott JM: Maternal plasma folate and vitamin $\mathrm{B} 12$ are independent risk factors for neural tube defects. Q J Med 1993, 86:703-708.

11. MRC Vitamin Study Research Group: Prevention of neural tube defects: results of the Medical Research Council Vitamin Study. Lancet 1991, 338:131-137.

12. Czeizel AE, Dudas I: Prevention of the first occurrence of neural-tube defects by periconceptional vitamin supplementation. N Engl J Med 1992, 327:1832-1835.

13. Frosst P, Blom HJ, Milos R, Goyette P, Sheppard CA, Matthews RG, Boers GJ, den Heijer M, Kluijtmans LA, van den Heuvel LP: A candidate genetic risk factor for vascular disease: a common mutation in methylenetetrahydrofolate reductase. Nat Genet 1995, 10:111-113.

14. Botto LD, Yang Q: 5,10-Methylenetetrahydrofolate reductase gene variants and congenital anomalies: a HuGE review. Am J Epidemiol 2000, 151:862-877.

15. Zhang T, Lou J, Zhong R, Wu J, Zou L, Sun Y, Lu X, Liu L, Miao X, Xiong G. Genetic variants in the folate pathway and the risk of neural tube defects: a meta-analysis of the published literature. PLOS One 2013, 8:e59570.
16. Doudney K, Grinham J, Whittaker J, Lynch SA, Thompson D, Moore GE, Copp AJ, Greene ND, Stanier P: Evaluation of folate metabolism gene polymorphisms as risk factors for open and closed neural tube defects. Am J Med Genet A 2009, 149A:1585-1589.

17. Brody LC, Conley M, Cox C, Kirke PN, McKeever MP, Mills JL, Molloy AM, O'Leary VB, Parle-McDermott A, Scott JM, Swanson DA: A polymorphism, $\mathrm{R} 653 \mathrm{Q}$, in the trifunctional enzyme methylenetetrahydrofolate dehydrogenase/methenyltetrahydrofolate cyclohydrolase/ formyltetrahydrofolate synthetase is a maternal genetic risk factor for neural tube defects: report of the Birth Defects Research Group. Am J Hum Genet 2002, 71:1207-1215.

18. De Marco P, Merello E, Calevo MG, Mascelli S, Raso A, Cama A, Capra V: Evaluation of a methylenetetrahydrofolate-dehydrogenase 1958G > A polymorphism for neural tube defect risk. J Hum Genet 2006, 51:98-103.

19. Parle-McDermott A, Kirke PN, Mills JL, Molloy AM, Cox C, O'Leary VB, Pangilinan F, Conley M, Cleary L, Brody LC, Scott JM: Confirmation of the R653Q polymorphism of the trifunctional C1-synthase enzyme as a maternal risk for neural tube defects in the Irish population. Eur J Hum Genet 2006, 14:768-772.

20. van der Linden IJ, Heil SG, Kouwenberg IC, den Heijer M, Blom HJ: The methylenetetrahydrofolate dehydrogenase (MTHFD1) 1958G > A variant is not associated with spina bifida risk in the Dutch population. Clin Genet 2007, 72:599-600.

21. Franke B, Vermeulen SH, Steegers-Theunissen RP, Coenen MJ, Schijvenaars MM, Scheffer H, den Heijer M, Blom HJ: An association study of 45 folate-related genes in spina bifida: Involvement of cubilin (CUBN) and tRNA aspartic acid methyltransferase 1 (TRDMT1). Birth Defects Res A Clin Mol Teratol 2009, 85:216-226.

22. Yang M, Yang L, Qi L, Guo Y, Lin X, Zhang Y, Du Y: Association between the methionine synthase A2756G polymorphism and neural tube defect risk: a meta-analysis. Gene 2013, 520:7-13.

23. Morrison K, Papapetrou C, Hol FA, Mariman EC, Lynch SA, Burn J, Edwards $\mathrm{YH}$ : Susceptibility to spina bifida; an association study of five candidate genes. Ann Hum Genet 1998, 62:379-396.

24. Christensen B, Arbour L, Tran P, Leclerc D, Sabbaghian N, Platt R, Gilfix BM, Rosenblatt DS, Gravel RA, Forbes P, Rozen R: Genetic polymorphisms in methylenetetrahydrofolate reductase and methionine synthase, folate levels in red blood cells, and risk of neural tube defects. Am J Med Genet 1999, 84:151-157.

25. Akar N, Akar E, Deda G, Arsan S: Spina bifida and common mutations at the homocysteine metabolism pathway. Clin Genet 2000, 57:230-231.

26. Johanning GL, Tamura T, Johnston KE, Wenstrom KD: Comorbidity of 5,10-methylenetetrahydrofolate reductase and methionine synthase gene polymorphisms and risk for neural tube defects. J Med Genet 2000 37:949-951.

27. De Marco P, Calevo MG, Moroni A, Arata L, Merello E, Finnell RH, Zhu H, Andreussi L, Cama A, Capra V: Study of MTHFR and MS polymorphisms as risk factors for NTD in the Italian population. J Hum Genet 2002, 47:319-324.

28. Zhu H, Wicker NJ, Shaw GM, Lammer EJ, Hendricks K, Suarez L, Canfield M, Finnell $\mathrm{RH}$ : Homocysteine remethylation enzyme polymorphisms and increased risks for neural tube defects. Mol Genet Metab 2003, 78:216-221.

29. Brouns R, Ursem N, Lindemans J, Hop W, Pluijm S, Steegers E, SteegersTheunissen R: Polymorphisms in genes related to folate and cobalamin metabolism and the associations with complex birth defects. Prenat Diagn 2008, 28:485-493.

30. De Marco P, Calevo MG, Moroni A, Merello E, Raso A, Finnell RH, Zhu H, Andreussi L, Cama A, Capra V: Reduced folate carrier polymorphism (80A- > G) and neural tube defects. Eur J Hum Genet 2003, 11:245-252.

31. Wang HG, Wang JL, Zhang J, Zhao LX, Zhai GX, Xiang YZ, Chang P: Reduced folate carrier A80G polymorphism and susceptibility to neural tube defects: a meta-analysis. Gene 2012, 510:180-184.

32. Relton CL, Wilding CS, Pearce MS, Laffling AJ, Jonas PA, Lynch SA, Tawn EJ Burn J: Gene-gene interaction in folate-related genes and risk of neural tube defects in a UK population. J Med Genet 2004, 41:256-260.

33. Shaw GM, Lammer EJ, Zhu H, Baker MW, Neri E, Finnell RH: Maternal periconceptional vitamin use, genetic variation of infant reduced folate carrier (A80G), and risk of spina bifida. Am J Med Genet 2002, 108:1-6.

34. Johnson WG, Stenroos ES, Spychala JR, Chatkupt S, Ming SX, Buyske S: New $19 \mathrm{bp}$ deletion polymorphism in intron-1 of dihydrofolate reductase (DHFR): a risk factor for spina bifida acting in mothers during pregnancy? Am J Med Genet A 2004, 124A:339-345. 
35. Parle-McDermott A, Pangilinan F, Mills JL, Kirke PN, Gibney ER, Troendle J, O'Leary VB, Molloy AM, Conley M, Scott JM, Brody LC: The 19-bp deletion polymorphism in intron-1 of dihydrofolate reductase (DHFR) may decrease rather than increase risk for spina bifida in the Irish population. Am J Med Genet A 2007, 143A:1174-1180.

36. van der Linden IJ, Nguyen U, Heil SG, Franke B, Vloet S, Gellekink H, den Heijer M, Blom HJ: Variation and expression of dihydrofolate reductase (DHFR) in relation to spina bifida. Mol Genet Metab 2007, 91:98-103.

37. Valachis A, Mauri D, Neophytou C, Polyzos NP, Tsali L, Garras A, Papanikolau EG: Translational medicine and reliability of single-nucleotide polymorphism studies: can we believe in SNP reports or not? Int J Med Sci 2011, 8:492-500

38. Munafo MR, Clark TG, Flint J: Assessing publication bias in genetic association studies: evidence from a recent meta-analysis. Psychiatry Res 2004, 129:39-44.

39. Dwan K, Altman DG, Arnaiz JA, Bloom J, Chan AW, Cronin E, Decullier E, Easterbrook PJ, Von Elm E, Gamble C, Ghersi D, loannidis JP, Simes J, Williamson PR: Systematic review of the empirical evidence of study publication bias and outcome reporting bias. PLoS One 2008, 3:e3081.

40. Kyzas PA, Denaxa-Kyza D, loannidis JP: Almost all articles on cancer prognostic markers report statistically significant results. Eur J Cancer 2007, 43:2559-2579.

41. Shaw GM, Lu W, Zhu H, Yang W, Briggs FB, Carmichael SL, Barcellos LF, Lammer EJ, Finnell RH: 118 SNPs of folate-related genes and risks of spina bifida and conotruncal heart defects. BMC Med Genet 2009, 10:49.

42. Lu W, Guzman AR, Yang W, Chapa CJ, Shaw GM, Greene RM, Pisano MM, Lammer EJ, Finnell $\mathrm{RH}$, Zhu H: Genes encoding critical transcriptional activators for murine neural tube development and human spina bifida: a case-control study. BMC Med Genet 2010, 11:141.

43. Martinez CA, Northrup H, Lin Jl, Morrison AC, Fletcher JM, Tyerman GH, Au KS: Genetic association study of putative functional single nucleotide polymorphisms of genes in folate metabolism and spina bifida. Am J Obstet Gynecol 2009, 201(394):e311-e391.

44. Carter TC, Pangilinan F, Troendle JF, Molloy AM, VanderMeer J, Mitchell A, Kirke PN, Conley MR, Shane B, Scott JM, Brody LC, Mills JL: Evaluation of 64 candidate single nucleotide polymorphisms as risk factors for neural tube defects in a large Irish study population. Am J Med Genet A 2011, 155A:14-21.

45. Pangilinan F, Molloy AM, Mills JL, Troendle JF, Parle-McDermott A, Signore C, O'Leary VB, Chines P, Seay JM, Geiler-Samerotte K, Mitchell A, VanderMeer JE, Krebs KM, Sanchez A, Cornman-Homonoff J, Stone N, Conley M, Kirke PN, Shane B, Scott JM, Brody LC: Evaluation of common genetic variants in 82 candidate genes as risk factors for neural tube defects. BMC Med Genet 2012, 13:62.

46. Spielman RS, McGinnis RE, Ewens WJ: Transmission test for linkage disequilibrium: the insulin gene region and insulin-dependent diabetes mellitus (IDDM). Am J Hum Genet 1993, 52:506-516.

47. Pangilinan F, Mitchell A, VanderMeer J, Molloy AM, Troendle J, Conley M, Kirke PN, Sutton M, Sequeira JM, Quadros EV, Scott JM, Mills JL, Brody LC: Transcobalamin II receptor polymorphisms are associated with increased risk for neural tube defects. J Med Genet 2010, 47:677-685.

48. Hol FA, van der Put NM, Geurds MP, Heil SG, Trijbels FJ, Hamel BC, Mariman EC, Blom HJ: Molecular genetic analysis of the gene encoding the trifunctional enzyme MTHFD (methylenetetrahydrofolate-dehydrogenase, methenyltetrahydrofolate-cyclohydrolase, formyltetrahydrofolate synthetase) in patients with neural tube defects. Clin Genet 1998, 53:119-125.

49. Saavedra-Matiz CA, Isabelle JT, Biski CK, Duva SJ, Sweeney ML, Parker AL, Young AJ, Diantonio LL, Krein LM, Nichols MJ, Caggana M: Cost-effective and scalable DNA extraction method from dried blood spots. Clin Chem 2013, 59:1045-1051.

50. Browne ML, Carter TC, Kay DM, Kuehn D, Brody LC, Romitti PA, Liu A, Caggana M, Druschel CM, Mills $J$ : Evaluation of genes involved in limb development, angiogenesis, and coagulation as risk factors for congenital limb deficiencies. Am J Med Genet A 2012, 158A:2463-2472.

51. Gorroochurn P, Hodge SE, Heiman GA, Durner M, Greenberg DA: Nonreplication of association studies: "pseudo-failures" to replicate? Genet Med 2007, 9:325-331

52. Zollner S, Pritchard JK: Overcoming the winner's curse: estimating penetrance parameters from case-control data. Am J Hum Genet 2007, 80:605-615.
53. Au KS, Ashley-Koch A, Northrup H: Epidemiologic and genetic aspects of spina bifida and other neural tube defects. Dev Disabil Res Rev 2010, 16:6-15.

54. Shaw GM, Rozen R, Finnell RH, Wasserman CR, Lammer EJ: Maternal vitamin use, genetic variation of infant methylenetetrahydrofolate reductase, and risk for spina bifida. Am J Epidemiol 1998, 148:30-37.

55. Volcik KA, Shaw GM, Zhu H, Lammer EJ, Laurent C, Finnell RH: Associations between polymorphisms within the thymidylate synthase gene and spina bifida. Birth Defects Res A Clin Mol Teratol 2003, 67:924-928.

56. Lupo PJ, Canfield MA, Chapa C, Lu W, Agopian AJ, Mitchell LE, Shaw GM, Waller DK, Olshan AF, Finnell RH, Zhu H: Diabetes and obesity-related genes and the risk of neural tube defects in the national birth defects prevention study. Am J Epidemiol 2012, 176:1101-1109.

57. Ubbink JB, Christianson A, Bester MJ, Van Allen MI, Venter PA, Delport R, Blom HJ, van der Merwe A, Potgieter H, Vermaak WJ: Folate status, homocysteine metabolism, and methylene tetrahydrofolate reductase genotype in rural South African blacks with a history of pregnancy complicated by neural tube defects. Metabolism 1999, 48:269-274.

58. Yan L, Zhao L, Long Y, Zou P, Ji G, Gu A, Zhao P: Association of the maternal MTHFR C677T polymorphism with susceptibility to neural tube defects in offsprings: evidence from 25 case-control studies. PLoS One 2012, 7:e41689.

59. van der Put NM, Eskes TK, Blom HJ: Is the common $677 \mathrm{C}->$ T mutation in the methylenetetrahydrofolate reductase gene a risk factor for neural tube defects? A meta-analysis. QJM 1997, 90:111-115.

60. Ouyang S, Li Y, Liu Z, Chang H, Wu J: Association between MTR A2756G and MTRR A66G polymorphisms and maternal risk for neural tube defects: a meta-analysis. Gene 2013, 515:308-312.

61. van der Linden IJ, den Heijer M, Afman LA, Gellekink H, Vermeulen SH, Kluijtmans LA, Blom HJ: The methionine synthase reductase $66 \mathrm{~A}>\mathrm{G}$ polymorphism is a maternal risk factor for spina bifida. $J \mathrm{Mol}$ Med (Berl) 2006, 84:1047-1054.

62. Ouyang S, Liu Z, Li Y, Wu J: Meta-analyses on the association of MTR A2756G and MTRR A66G polymorphisms with neural tube defect risks in Caucasian children. J Matern Fetal Neonatal Med 2013, 26(12):1166-1170.

doi:10.1186/s12881-014-0102-9

Cite this article as: Pangilinan et al:: Replication and exploratory analysis of 24 candidate risk polymorphisms for neural tube defects. $B M C$ Medical Genetics 2014 15:102.

\section{Submit your next manuscript to BioMed Central and take full advantage of:}

- Convenient online submission

- Thorough peer review

- No space constraints or color figure charges

- Immediate publication on acceptance

- Inclusion in PubMed, CAS, Scopus and Google Scholar

- Research which is freely available for redistribution 